\title{
PENGARUH NORMA HAM DI DUNIA INTERNASIONAL TERHADAP FENOMENA REFORMASI 1998 DI INDONESIA
}

\author{
Ardli Johan Kusuma \\ Prodi Ilmu Hubungan Internasional, Fakultas Ilmu Sosial Ilmu Politik, \\ Universitas 17 Agustus 1945 Jakarta. \\ Email: ardli.johan@yahoo.com
}

\begin{abstract}
Abstrak
Tulisan ini membahas terkait peristiwa reformasi yang terjadi di Indonesia pada tahun 1998. Dimana ketika itu rakyat Indonesia menuntut pemerintah untuk menyelenggarakan sistem pemerintahan yang lebih demokratis dan lebih menghargai HAM. Adapun penelitian ini menggunakan metode kualitatif, adapun data-data yang digunakan dari penelitian ini adalah data sekunder yang diperoleh melalui teknik pengumpulan data "librarian research", dimana data diperoleh dari sumber-sumber pustaka seperti buku, jurnal, koran, majalah, dokumen laporan, serta sumber-sember yang berasal dari internet. Adapun temuan dalam penelitian ini adalah adanya relasi antara peristiwa reformasi di Indonesia dengan perkembangan norma HAM di dunia internasional. Indonesia beradaptasi dengan nilai yang berkembang di dunia internasional melalui peristiwa reformasi untuk membentuk sistem pemerintahan yang sesuai dengan apa yang sedang berkembang di dunia internaional yaitu terkait perkembangan norma HAM itu sendiri, melalui sebuah mekanisme yang disebut Process of Norms Socialization (proses sosialisasi norma). dengan kata lain peristiwa reformasi di Indonesia telah dipengarui oleh perkembangan norma HAM di dunia internasional.
\end{abstract}

Keywords: Reformasi, Hak Asasi Manusia, Indonesia, Norma Internasional, Proses sosialisasi norma

\begin{abstract}
This article discusses the events related to reforms that occurred in Indonesia in 1998. Where at that time the people of Indonesia demanded the government to organize a more democratic system of government and more respect for human rights. The research uses qualitative method, while the data used from this research is secondary data obtained through the technique of collecting data "librarian research", where data obtained from literature sources such as books, journals, newspapers, magazines, document reports, as well as sources derived from the internet. The findings in this study is a relationship between reform events in Indonesia with the development of international human rights norms. Indonesia adapts to the growing value of the international world through reform events to establish a system of government in accordance with what is developing in the international world that is related to the development of the human rights norm itself, through a mechanism called Process of Norms Socialization (the process of socialization of the norm). in other words the reform event in Indonesia has been influenced by the development of international human rights norms.
\end{abstract}

Keywords: Reform, Human Rights, Indonesia, International Norms, Socialization of norm. 


\section{PENDAHULUAN}

Pada tahun 1998 Indonesia mengalami sebuah fase yang disebut dengan reformasi. Fase ini menjadi titik balik bagi Indonesia yang merubah sistem pemerintahan yang otoriter dibawah presiden Soeharto, diganti dengan sistem yang demokratis. Proses reformasi ini merupakan bentuk adaptasi Indonesia atas berkembangnya norma demokrasi dan perlindungan HAM yang sudah dikembangkan di berbagai negara di dunia. dengan kondisi tersebut Indonesia telah menyesuaikan diri dengan lingkungan internasional yang sedang mengembangkan nilai-nilai demokrasi dan perlindungan HAM.

Indonesia mengalami sejarah yang cukup panjang semenjak proklamasi kemerdekaan yang dilakukan oleh pendiri bangsa yang sekaligus menjadi presiden pertama yaitu Soekarno. Era kepemimpinan Soekarno di Indonesia lebih dikenal dengan sebutan era Orde Lama, yaitu masa kekuasaan yang dimulai sejak tahun 1945 sampai 1966.

Setelah itu kekuasaan Soekarno lengser dan digantikan seorang pemimpin yang berlatar belakang dari militer, yaitu Soeharto. Dan era kepemimpinan Soharto ini dikenal dengan sebutan era Orde Baru yang menggantikan era sebelumnya. Era orde baru ini ditandai dengan sistem pemerintahan yang dianggap otoriter dan tidak menghargai HAM. Rezim ini berkuasa kurang lebih 32 tahun dengan militer yang menjadi tumpuan utama bagi pemerintah waktu itu (Kusuma, 2016).

Hal tersebut kemudian membuat rakyat Indonesia secara berlahan tapi pasti meluapkan kekecewaan dengan menuntut presiden Soeharto unuk turun dan merubah sistem pemerintahan untuk lebih demokratis dan lebih menghargai HAM. Hal itu tidak lepas dari pengaruh perkembangan norma HAM dan demokrasi di dunia internasional yang kemudian membuat Indonesia mau tidak mau beradaptasi dengan kondisi tersebut. Identitas Indonesia yang pada dasarnya adalah negara yang demokratis dilihat dari konstitusinya, kemudian menyesuaikan diri dengan perkembangan di dunia internasinal untuk merealisasikan identitasnya sebagai sebuah negara yang demokratis dan menghargai HAM.

\section{Kerangka Pemikiran}

\section{The Power of Norms}

Untuk menganalisa terkait masalah yang diangkat dalam penelitian ini yaitu terkait peristiwa reformasi di Indonesia, penulis menggunakan model the power of norms. Model ini akan menjelaskan bagaimana sebuah norma yang berkembang didunia internasional dapat mempengaruhi sebuah negara melalui proses interaksi dalam dunia internasional. 
Para kaum konstruktivisme dalam Ilmu Hubungan Internasional pada dasarnya telah berasumsi bahwa politik internasional merupakan hasil dari suatu "konstruksi sosial", dalam hal ini adalah proses dialektika antara "struktur" dan "agen", dimana lingkungan sosial-politik dan manusia saling berinteraksi untuk menghasilkan perubahan-perubahan sosial-politik.

Sementara dalam proses interaksi yang terjadi antar aktor internasional tersebut, baik agen maupun struktur dipengaruhi oleh norma atau nilai-nilai yang ada. Norma yang berkembang akan mempengaruhi aktor yang saling berinteraksi untuk membentuk suatu identitas bersama yang akan bisa mempengaruhi kepentingan dan perilaku aktor internasional, termasuk negara.

Identitas yang akan mempengaruhi kepentingan dan perilaku aktor hubungan internasional termasuk negara, dapat dipengaruhi oleh norma yang sedang berkembang melalui sebuah proses yang disebut "sosialisasi norma" (norms socialization). Dimana dalam proses sosialisasi tersebut, sebuah norma melalui beberapa tahapan yang kemudian bisa membentuk identitas dan kepentingan sebuah negara sesuai dengan norma yang berkembang tersebut. "three types of socialization process: 1) processes of adaptation and strategic bargaining; 2) processes of moral consciousness-raising, "shaming", argumentation, dialogue, and persuasion; 3) prosesses of institutionalization and habitualization" (Thomas, 1999).

Untuk mempermudah pemahaman kita terhadap proses norms socialization, berikut ini ada sebuah gambar model dari proses tersebut yang akan menjelaskan tentang bagaimana tahapan-tahapan yang dilalui sebuah norma yang kemudian bisa mempengaruhi identitas dan kepentingan sebuah negara. 
Gambar 1. Model Process of Norms Socialization Thomas Risse dkk

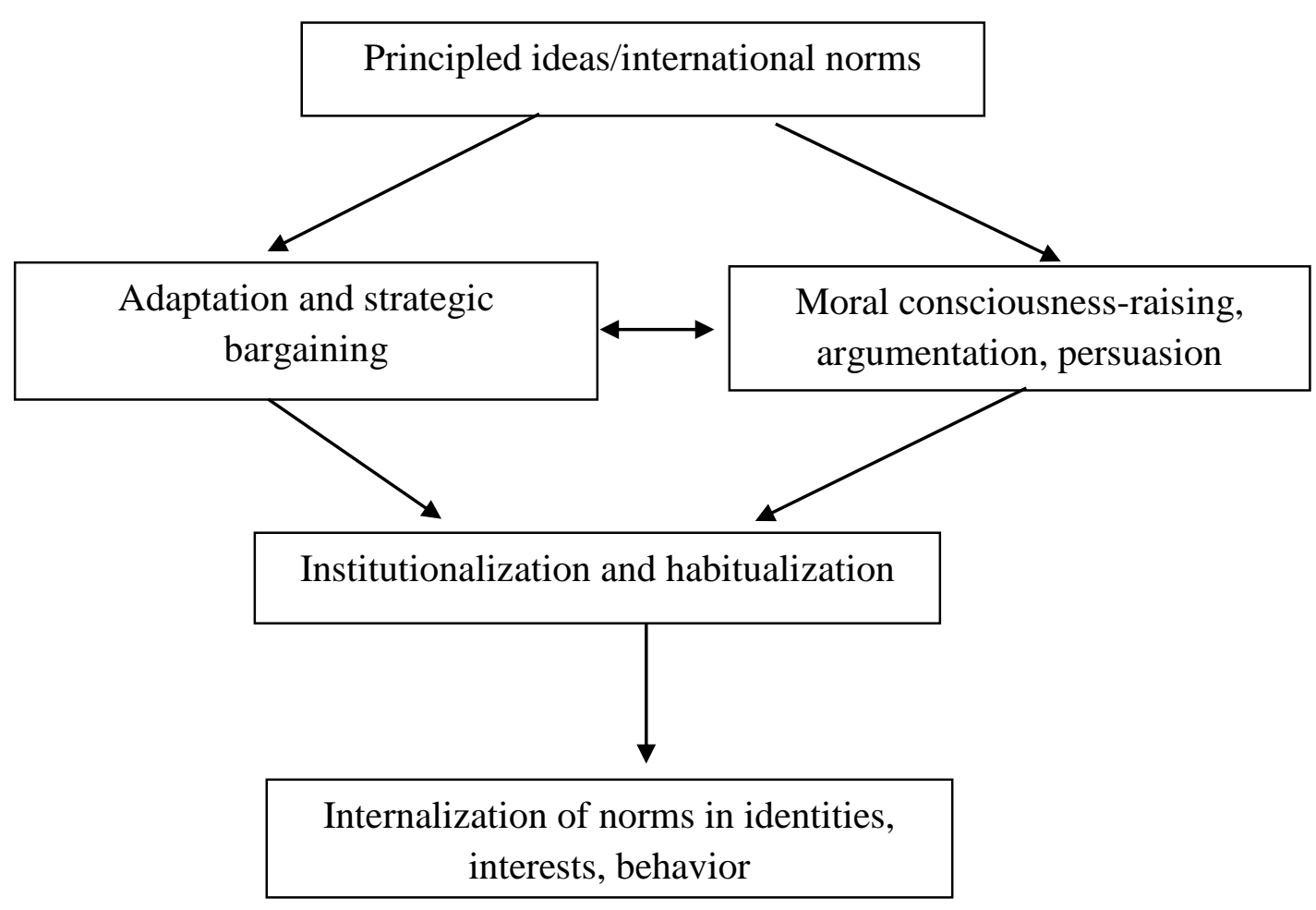

The Process of Norms Socialization.

(sumber: Thomas Risse dkk, "The Power of Human Rights-International Norms and Domestic Change", New York, Cambridge University Press, 1999, hal 12.)

Pada dasarnya Norms Socialization adalah sebuah proses yang menunjukkan bahwa sebuah norma internasional mampu mempengaruhi identitas sebuah negara, dimana identitas tersebut akan menuntun negara itu pada sebuah kepentingan dan perilaku yang sesuai dengan norma yang ada tersebut.

\section{PEMBAHASAN}

\section{HAM Dan Demokrasi Menjadi Agenda Dunia Internasional}

Sejak adanya Deklarasi Universal Hak asasi manusia, pada 10 Desember 1948 yang diselenggarakan oleh PBB, maka berangsur-angsur negara-negara di dunia mulai mengadopsi sistem pemerintahan yang demkratis yang dianggap sebagai sistem yang paling bisa mengakomodasi niliai-nilai hakasasi manusia. Bahkan HAM dana demokrasi menjadi salah satu instrumen penting yang sangat berpengaruh dalam pola hubungan antar negara. 
Universal Declaration of Human Rights (Deklarasi Universal Hak asasi manusia). Deklarasi universal ini diselenggarakan atas dasar resolution 217 A (III) of 10 December 1948 (United Nations, n.d.). Deklarasi ini membuahkan 30 butir pasal yang semuanya berinti pada penghormatan atas HAM.

Deklarasi Universal HAM telah disepakati dalam Majelis Umum PBB pada 1948. Deklarasi ini dapat dimaknasi sebagi bentuk aplikatif dari Piagam PBB, yang memuat lebih rinci terkait hak-hak dasar manusia. Deklarasi tersebut merupakan bentuk dari "standar pencapaian bersama". Untuk itu dalam perwujudannya dinyatakan dalam bentuk deklarasi dan bukan bentuk perjanjian internasional. pada kenyataannya deklarasi ini dipandang sebagai suatu pencapaian besar, karena banyak negara yang mengakui legalitas dari deklarasi tersebut untuk menjadi salah satu instrumen hukum internasional yang harus ditaati oleh semua negara anggota PBB (Pusham UII, n.d.).

Semenjak runtuhnya Tembok Berlin dan berakhirnya perang dingin, promosi demokrasi dan hak-hak asasi manusia (HAM) telah menjadi tujuan utama negara donor internasional. Akibatnya, dalam setiap kerjasama dengan negara-negara peminjam, berbagai negara donor dan lembaga keuangan internasional cenderung untuk selalu melampirkan berbagai syarat yang disebut kriteria politik, seperti pengakuan HAM, partisipasi masyarakat dalam politk dan penegakan hukum, bahkan termasuk pula isu gender dan lingkungan.

Setelah perang dingin berakhir (sekitar akhir 1980-an dan awal 1990-an), secara mendadak memang seolah menghapus semua kerangka politik internasional yang telah mengakar selama kurun 40 tahun. Ketika Perang Dingin berakhir sebenarnya sempat muncul harapan besar adanya suatu sistem multilateralis, tetapi ternyata dalam perjalanannya, ketika AS menjadi satu-satunya negara adidaya yang dominan, akhirnya terdapat kecenderungan untuk melakukan langkah-langkah yang sifatnya unilateralis. Negara-negara barat yang tidak lain adalah AS dan Eropa yang menjadi pemenang seolah meyakini, dan oleh karena itu memaksa orang lain pula unuk meyakini bahwa berbagai nilai kebebasan yang mereka kembangkan adalah sebuah kebenaran yang harus pula dikembangkan di berbagai kawasan lain. Dalam konteks ini terjadi apa yang dinamakan globalisasi HAM dan demokrasi versi barat. Bahkan, mereka seolah tampil sebagai pemegang otoritas penegakan HAM dan demokrasi (Pusham UII, n.d.). Namun pada kenyataannya sejak diadakannya Deklarasi Universal Hak asasi manusia pada 1948, secara pelan tapi pasti banyak negara yang mulai mengadopsi nilai HAM untuk dijadikan patokan dalam sistem penyelenggaraan suatu negara. Nilai HAM dan demokrasi menjadi agenda 
internasional yang diyakini sebagai nilai universal yang harus diterapkan di setiap negara di dunia.

\section{Tentang Orde Baru di Indonesia}

Era Orde Baru (Orba) adalah rezim di Indonesia yang diidentikan dengan kepemimpinan Soeharto, yaitu dari 12 Maret 1967 sampai dengan 21 Mei 1998. Namun demikian, hal itu perlu dicatat bahwa sejak terjadinya kegagalan kudeta Gerakan 30 September 1965 oleh Partai Komunis Indonesia (G-30S/PKI) Soeharto telah mendapatkan kekuasaan melalui Supersemar sebagai Komando Pemulihan Keamanan pada 12 Maret 1966 (meskipun keberadaan Surat Perintah 11 Maret atau Supersemar tahun 1966 sampai saat ini keberadaannya masih kontroversial). Masa kepemimpinan Soeharto tersebut, yang dikenal dengan sebutan era Orde Baru, mencapai 32 tahun dan termasuk masa kepemimpinan yang paling panjang dibandingkan dengan masa kepemimpinan sebelumnya maupun sesudahnya. Panjangnya rentang waktu, membuat dinamika politik dan ekonomi masa Soeharto mempunyai suatu pola tertentu, tidak hanya dalam hal politik dalam negeri tetapi juga politik luar negeri Indonesia (Wuryandari, 2008).

Era Orde Baru di bawah kepemimpinan Soeharto disebut-sebut sebagai gaya kepemimpinan yang otoriter, dan seringkali membawa militer sebagai solusi penyelesaian masalah politik yang terjadi di Indonesia. Mengingat latar belakan Soeharto adalah dari militer. Selain pengaruhnya yang besar bagi perjalanan sejarah untuk bangsa Indonesia, Soeharto juga sangat berpengaruh bagi perjalanan sejarah rakyat Timor Leste. Karena invasi yang dilakukan tentara Indonesia melalui operasi Seroja pada tahun 1975, merupakan operasi yang saat itu diputuskan oleh presiden Soeharto.

Gaya kepemimpinan Soeharto sangat bertolak belakang dengan sistem demokarsi yang seharusnya diterapkan di Indonesia berdasarkan amanat konstitusi negara Indonesia. Namun ppenerapan dari bentuk-bentuk beberapa kebijakan yang diambil oleh Soeharti justru bertolak belakang dengan asas-asas demokrasi. Misalnya kebijakan Soeharto terhadap media dianggap sebagai kebijakan yang melawan demokrasi. Dalam demokrasi media seharusnya menjadi salah satu pilar penting. Tetapi pada era Orde Baru gerak media sangat dibatasi oleh kekuasaan Soeharto (Purba, 2006).

Selain mempersempit gerak media untuk mengamankan kekuasaannya, Soeharto juga membatasi gerak ruang partai politik yang seharusnya menjadi media untuk terserapnya aspirasi dan pengelolaan partisipasi masyarakat dalam kancah politik. Bersama dengan Golkar, Soeharto melakukan segala cara untuk selalu memenangi pemilu. Hal ini 
ditunjukkan dengan kemenangan-kemenangan dalam beberapa kali pemilu yang dicapai oleh Golkar, dan menempatkan Soeharto sebagai presiden.

Pada era Orde Baru, pemilu pertama yang menjadi momentum kemenangan mutlak rezim otoriter ini terjadi pada tahun 1971. Dimana waktu itu kekuatan orde baru diorganisasi di dalam Golkar, dengan memperoleh suara 65 persen. Kemenangan tersebut diperoleh dengan melakukan rekayasa politik. Kebijakan yang diambil pada waktu itu adalah pelarangan terhadap partai politik yang menjadi lawan rezim ini untuk berhubungan dengan para pemilihnya sampai level bawah. Ketika itu partai diluar rezim hanya boleh memiliki kepengurusan hanya sampai level kabupaten, dan tidak boleh sampai level kecamatan dan desa. Sementara Golkar yang ketika itu mendeklarasikan dirinya bukan sebagai kekuatan partai politik dapat menjalin relasi dengan para pemilih bahkan sampai pada level RT dan RW. Pelemahan terhadap partai politik waktu itu terus berlanjut hingga menjelang pemilu tahun 1977, dengan menyederhanakan parati politik dari 10 partai menjadi hanya 3 partai. Penyederhanaan dilakukan secara tidak lazim dan dengan cara sewenang-wenang. Partai politik yang memiliki latar belakan Islam seperti Partai NU, Parmusi, PSII, dan Perti dilebur dalam satu partai yaitu Partai Persatuan Pembangunan (PPP). Partai yang memiliki latar belakang nasionalis seperti PNI, dan non-Islam seperti Partai Kristen Indonesia (Parkindo), disatukan kedalam Partai Demokrasi Indonesia (PDI). Dua partai politik ini diharuskan bertarung menghadapi kekuatan "negara", yaitu Golkar. Hasil dari penyederhanaan itu menyebabkan dua partai hasil penyederhanaan itu kalah selama 6 kali pemilu selama Orde Baru berkuasa (Tempo, 2008).

Selain mempermainkan sistem politik untuk mengamankan posisinya Soeharto juga memainkan peran militer untuk menjaga kekuasaanya. Militer yang memiliki tugas ganda yang dikenal dengan istilah "Dwifunsi ABRI", membuat Soeharto lebih mudah mengordinir militer untuk tetap berpihak kepadanya dan mengamankan posisinya. Dengan fungsi militer yang memiliki tugas ganda tersebut, Soeharto sering menggunakan militer untuk menyelesaikan masalah yang berkaitan dengan politknya. Cara-cara ala militer sering dilakukan oleh Soeharto untuk menyelesaikan masalah.

Militer sering digunakan oleh Soeharto untuk melakukan tugas-tugas non-militer. Misalnya saja penumpasan premanisme yang dipegang oleh militer. Ribuan premanpreman pada waktu itu ditembak secara misterius oleh militer Indonesia dibawah perintah Soeharto. Dampak dari tugas-tugas non-militer yang dipegang oleh aparat militer adalah penurunan profesionalisme militer TNI. Sisi negatif dari kepemimpinan rezim Soeharto diperparah dengan masuknya pengaruh dari kroni serta keluarga Cendana. Bahkan hal 
tersebut mempengaruhi situasi internal jajaran militer. Masuknya keluarga dan kroni Cendana bahkan mengakibatkan seorang panglima ABRI ketika itu yaitu Jenderal L.B. Moerdani dicopot jabatannya oleh Soeharto karena tidak sependapat dengan Soeharto tentang keterlibatan keluarga Cendana dalam urusan kenegaraan. Militer waktu itu menjadi sebuah institusi yang seolah kebal hukum dan banyak melakukan kekerasan yang melanggar HAM. Rakyat pada umumnya tidak bersimpati dengan sepak terjang dari rezim orde baru dengan penggunaan kekuatan militernya yang sewenang-wenang (Tempo, 2008).

\section{Tekanan Atas Nama HAM dan Demokrasi Dari Komunitas Internasional Terhadap}

\section{Indonesia}

Menurut Thomas Risse sebuah norma internasional mampu mempengaruhi identitas sebuah negara, dimana identitas tersebut akan menuntun negara itu pada sebuah kepentingan dan perilaku yang sesuai dengan norma yang ada tersebut. dalam hal ini norma penghargaan atas HAM telah menjadi norma internasional (Thomas, 1999). Dan untuk menjamin HAM masyarakat internasional meyakini bahwa sistem demokrasi adalah sistem yang mampu menjamin penghargaan atas HAM. Dalam hal ini Amerika Serikat yang keluar sebagai pemenang perang dingin menjadi Norm entrepreneurs. Menurut Martha Finnemore dan Kathryn Sikkink sebuah norma bisa muncul dan diyakini kebenarannya oleh sebuah komunitas melalui proses sosialisasi yang dilakukan oleh Norm entrepreneurs (Finnemore \& Sikkink, 1998). Dalam arti AS menjadi agen yang ingin mensosialisasikan norma HAM dan nilai-nilai demokrasi.

Dengan kepentingan utuk terjadnya demokratisasi di Indonesia pemerintah AS melakukan tekanan-tekanan, misalnya pada Juni 1993 Amerika Serikat melancarkan tekanan diplomatik dengan memberikan ancaman kepada Indonesia akan pencabutan fasilitas GSP (Generalized System of Preferences) semacam fasilitas yang diberikan untuk meringankan beban pajak ekspor Indonesia ke Amerika Serikat. Hal ini dilakukan karena adanya peristiwa pelanggaran HAM yang dilakukan oleh pemerintah Indonesia ketika itu yaitu terbunuhnya seorang buruh pekerja di Jawa Timur. Kalangan aktivis HAM dan organisasi buruh di Amerika menganggap hal itu sebagai pelanggaran HAM. Mereka mendesak Clinton untuk mencabut fasilitas GSP bagi Indonesia karena peristiwa tersebut. jika fasilitas GSP dicabut, maka sekitar 14\% ekspor Indonesia ke Amerika Serikat akan dikenai bea-cukai, sehingga berpotensi merugikan perekonomian Indonesia. Oleh karena itu Asia Watch dan the International Labor Rights Education and Recearch Fund 
mendesak United States Trade Representatives (USTR) agar mencabut fasilitas GSP bagi Indonesia (Cipto, 2003).

Kemudian pada Agustus 1993 Indonesia kembali mendaat tekanan diplomatik dari Amerika Serikat. Hal ini terkait dengan rencana transfer pesawat F-5E dari Yordan ke Indonesia. Penolakan transfer pesawa F-5E ini terkait dengan pelanggaran HAM yang terjadi di Timor Leste, yang menjadi fokus alasan penolakan yang dilakukan oleh para saenator dan LSM di Amerika Serikat. Kelompok penentang utama rancana transfer pesawat tersebut adalah tokoh-tokoh kongres yang anti Indonesia. mereka adalah senator Claiborn Pell (D-RI) dan senator Russel Feingold (D-Wiscounsin). Senator Pell sangat kecewa terhadap pemerintah Indoensia karena tidak diijinkan mengunjungi Timor Timur dalam kunjungannya ke Indonesia tahun 1992. Kekecewaan ini berbuntut panjang dan menambah antipatinya terhadap pemerintah Indonesia yang dianggap tidak demokratis dan tidak menghargai HAM. selain itu sebagai Ketua Komisi Luar Negeri, Pell paham betul bahwa setiap transfer pesawat buatan Amerika Serikat harus mendapat persetujuan dari Kongres. Oleh karena itu, isu transfer pesawat militer buatan Amerika Serikat dari Yordan ke Indoensia menjadi sasaran empuk bagi senator Pell, yang masih sangat kecewa dengan kondisi HAM di Timor Timur. Malalui surat yang ditujukan kepada Menteri Luar Negeri Warren Christopher, senator Pell yang didukung oleh senator Feingold menentang keras transfer pesawat F-5E ke Indonesia.

Bahkan ditahun yang sama Indonesia hampir saja tidak bisa menikmati bantuan luar negeri dari Amerika Serikat. Hal ini disebabkan oleh rencana perubahan RUU Amerikat terkait pemberian bantuan luar negeri dan penjualan senjata kepada Indonesia. munculnya isu tersebut terkait peristiwa Santa Cruz (Pembantaian di Timor Leste yang dilakukan Indoensia). Yang membuat beberapa senator yang masuk dalam kubu Feingold mendesak pemerintah Amerika untuk tidak lagi memberikan bantuan luar negeri dan penjualan senjata kepada Indonesia, melalui perubahan RUU Apropriasi Bantuan Luar Negeri untuk tahun anggaran 1994 (Cipto, 2003). Namun desakan dari para senator yang anti Indonesia ini gagal dan tidak berhasil melakukan perubahan RUU tersebut. Namun hal tersebut cukup membuat Indonesia merasa cemas karena bantuan Luar Negeri yang diberikan oleh Amerika Serikat cukup berarti bagi Indonesia.

Tekanan-tekanan yang diberikan oleh Amerika Serikat terhadap Indonesia tidak terlepas dari isu penghargaan terhadap HAM dan nilai-nilai demokrasi. Dimana pemerintah Amerika Serikat menganggap bahwa pemerintah Indonesia belum mampu menyelenggarakan jalannya pemerintahan dengan sistem yang demokratis dan menghargai 
HAM, dimana pemerintah AS ketika itu memiliki kepentingan untuk melakukan demokratisasi di berbagai negara sebagai dampak lanjutan atas menangnya AS dalam perang dingin untuk melawan komunisme.

Selain mendapatkan tekanan dari pemerintah super power yaitu AS, tekanan untuk Indonesia agar melaksanakan demokratisasi serta menghargai HAM juga datang dari lembaga-lembaga ekonomi yang biasa memberikan donor kepada negara-negara termasuk Indonesia. di era akhir tahun 1090-an, Indonesia mengalami krisis ekonomi yang luar biasa. dan saat itu, Indonesia membutuhkan suntikan dana dari lembaga keuangan internasional seperti IMF. Namun untuk mendapatkan bantuan atau pinjaman dana dari negara-negara dan organisasi ekonomi dan moneter internasional ini mengalami kendala. Hal ini disebabkan isu-isu demokrasi dan HAM yang menjadi salah satu syarat yang diajukan oleh organisasi-organisasi serta negara-negara yang akan menjadi donor dana bagi indonesia (Tarmidi, 1999).

Berbagai tekanan tersebut telah menunjukkan bahwa ketika sebuah nilai atau norma sudah dianggap sebagai suatu kebenaran bagi struktur internasional, akan bisa memberikan tekanan kepada agen-agen (dalam hal ini negara) untuk mengikuti norma tersebut. dan Indonesia telah mengalami berbagai tekanan untuk kemudian mengikuti norma yang dianggap benar oelh komunitas internasiona tersebut.

\section{Gerakan Reformasi di Indonesia}

Gaya kepemimpinan Soeharto yang dianggap tidak demokratis dan cenderung otoriter, mendapatkan kritikan serta tekanan dari dunia internasional yang kemudian juga memicu kemarahan rakyat Indonesia itu sendiri. Penolakan rakyat atas gaya kepemimpinan Soeharto diperparah dengan adanya krisis yang melanda Asia, termasuk Indonesia pada dekade 1990-an. Kemarahan rakyat dimotori oleh kaum mahasiswa yang menuntut Soeharto untuk turun dari jabatannya, dan menuntut adanya reformasi dalam sistem pemerintahan Indonesia.

Pada tahun 1998, gelombang demonstrasi dari para mahasiswa menjadi berita utama nasional. Para mahasiswa dari berbagai universitas di Indonesia melakukan aksi di berbagai daerah. Aksi yang diakukan oleh aktivis yang berasal dai kampus ini mengangkat berbagai macam isu. Namun pada intinya tuntutan yang diteriakkan sama yaitu menuntut adanya reformasi di bidang ekonomi dan bidang politik (J.A, 2006). Gerakan demonstrasi mahasiswa dan masyarakat tersebut diwarnai beberapa kerusuhan dan terjadinya pelanggaran HAM yang dilakukan oleh pemerintah Soeharto. 
Pada bulan Februari-Maret 1998, Sejumlah aktivis telah diculik. Penculikan ini merupakan bentuk upaya yang dilakukan oleh rezim penguasa pada waktu itu untuk meredam gelombang protes. Pada akhirnya kemudian diketahui bahwa penculikan tersebut telah dilakukan oleh Kopasus, yang pada saat itu dipimpin oleh Komandan Jenderal Mayjen Prabowo Subianto. Adapun beberapa aktifis yang diculik adalah: Andi Arif ,Nezar Patria, Desmon J. Mahesa, Pius Lustrilanang, Haryanto Taslam, Herman Hendrawan, Rahardjo Waluyo Djati, Faisal Riza, serta Mugianto. Bahkan Sebagian di antara para aktivis yang diculik hingga kini belum diketahui nasibnya. Dari kerusuhan yang terjadi telah tercatat 499 korban tewas dan lebih dari 4.000 gedung hancur atau terbakar akibat yang ditimbulkan dari kerusuhan. Kemudian puncak demonstrasi terjadi pada 18 Mei 1998, dimana ketika itu Ribuan mahasiswa di berbagai daerah menggelar demonstrasi untuk menuntut Soeharto turun dari jabatannya. Dan aksi yang paling monumental adalah ketika ribuan mahasiswa menduduki gedung DPR/MPR di Jakarta (Tempo, 2008). Akibat dari kuatnya desakan dari rakyat Indonesia, akhirnya pada tanggal 21 Mei 1998 Soeharto resmi mengundurkan diri dari jabatan presiden yang didudukinya selama 32 tahun.

Reformasi yang berhasil digulirkan dai tahun 1998, kemudian menghasilkan beberapa cita-cita atau agenda perubahan. Adapun agenda perubahan tersebut diantaranya adalah: pertama, pengusutan kasus korupsi dan kasus pelanggaran HAM yang terjadi selama rezim Soeharto berkuasa. Kedua, perubahan sitem pemilu untuk pemilihan presiden dan kepala daerah yang akan dipilih langsung oleh rakyat. Ketiga, penghapusan dwi-fungsi ABRI dan memisahkan kewenangan Polisi dan TNI. Kemudian yang tidak kalah penting adalah agenda untuk melaksanakan otonomi daerah, serta penuntutan agar anggaran pendidikan dialokasikan minimal 20\% dari APBN (Eriyanto, 2010).

Agenda reformasi yang menyusul lengsernya Soeharto membuka pintu baru bagi proses demokratisasi politik pemerintahan Indonesia selanjutnya. Agenda-agenda yang dibuat ketika reformasi adalah berdasarkan tuntutan tentang demokrasi yang selama kepemimpinan Soeharto tidak dilaksanakan dengan baik. Agenda reformasi yang menuntut kepastian hukum dan penghargaan atas HAM, serta penyelenggaraan pemerintahan yang lebih demokratis dan mengurangi dominasi peran militer dalam urusan politik (Mietzner, 2006). 


\section{KESIMPULAN}

Indonesia mengalami proses reformasi pada tahun 1998, yang mengganti sistem otoriter yang dipimpin oleh Soeharto. dan kemudian menggantinya dengan sistem demokrasi. Hal ini terjadi karena sistem demokrasi dikembangkan oleh banyak negara di dunia dan paska perang dingin sistem Demokrasi dan penghargaan atas HAM dianggap sebagai suatu nilai kebenaran universal yang menjadi identitas bersama masyarakat internasional. sehingga Indonesia yang melakukan interaksi dengan lingkungan internasional melakukan adaptasi dengan merubah sistem negaranya menjadi demokratis. Berbagai tekanan baik yang berasal dari luar maupun nasional terkait tuntutan terhadap pemerintah Indonesia untuk menyeenggarakan pemerintahan dengan demokratis dan menghargai HAM menjadi faktor penentu terjadinya reformasi di Indonesia untuk menjadi negara demokrasi.

\section{DAFTAR PUSTAKA}

Cipto, B. (2003). Tekanan Amerika Terhadap Indonesia. Yogyakarta: Pustaka Pelajar.

Eriyanto. (2010). 65 Tahun Kemerdekaan RI dan Pemenuhan Agenda Reformasi. Jurnal Sekretariat Negara RI, Agustus(17), 175.

Finnemore, M., \& Sikkink, K. (1998). International Norm Dynamics and Political Change. International Organization, 52(4), 887-917.

J.A, D. (2006). Jatuhnya Soeharto dan Transisi Demokrasi Indonesia. Yogyakarta: LKIS.

Kusuma, A. J. (2016). DINAMIKA NORMA HAK ASASI MANUSIA ( HAM ) DI INDONESIA : SEBUAH KONSTRUKSI REZIM INTERNASIONAL. Jurnal Etika \& Pemilu, 2(2), 25-43.

Mietzner, M. (2006). The Politics of Military Reform in Post-Suharto Indonesia : Elite Conflict, Nationalism, and Institutional Resistance. Washington: East-West Center Washington.

Purba, A. (2006). PERKEMBANGAN KEHIDUPAN PERS DARI MASA REZIM ORDE BARU KE MASA REZIM REFORMASI. Jurnal Wawasan, 12(1), 40-46.

Pusham UII. (n.d.). EVOLUSI PEMIKIRAN DAN SEJARAH PERKEMBANGAN HAK ASASI MANUSIA (pp. 7-39). Yogyakarta: Pusham UII.

Tarmidi, L. T. (1999). Krisis Moneter Indonesia : Sebab, Dampak, Peran IMF dan Saran. Buletin Ekonomi Moneter Dan Perbankan, (Maret).

Tempo. (2008). Edisi Khusus Soeharto. Tempo, 47. 
Thomas, R. K. S. (1999). The Socialization of International Human Rights Norms into Domestic Practices: Introduction. In K. S. Thomas Risse, Stephen C. Ropp (Ed.), The Power of Human Rights-International Norms and Domestic Change (pp. 1-38). Cambridge: Cambridge University Press.

United Nations. (n.d.). Universal Declaration of Human Rights. Retrieved July 23, 2018, from http://www.un.org/en/universal-declaration-human-rights/

Wuryandari, G. (2008). Politik Luar Negeri Indonesia di Tengah Pusaran Politik Domestik. Yogyakarta: Pustaka Pelajar. 